\title{
Qualitative Study on the Use and Maintenance of Long-Lasting Insecticidal Nets (LLINs) in Bouaké (Côte d'Ivoire), 17 Months After the Last Mass Distribution Campaign
}

\section{Gnagoran Kouakou Daniel N'GUESSAN ( $\sim$ gnagoran05@gmail.com )}

Centre d'Entomologie Médicale et Vétérinaire - Université Alassane Ouattara, Bouaké, Côte d'Ivoire https://orcid.org/0000-0002-5866-0146

\section{Fangala Hamidou COULIBALY}

Centre d'Entomologie Médicale et Vétérinaire - Université Alassane Ouattara, Bouaké, Côte d'Ivoire 2 MIVEGEC (Uuniv. Montpellier, IRD, CNRS), Institut de Recherche pour le Développement (IRD), Montpellier, France 3 Centre Suisse de Recherches Scientifiques en Côte d'Ivoire, Abidjan, Côte d'Ivoire

\section{Antoine Marc Gaby BARREAUX}

Bristol Veterinary School, University of Bristol, Bristol, UK CIRAD, UMR INTERTRYP, F-34398 Montpellier,

France INTERTRYP, Univ Montpellier, CIRAD, IRD, Montpellier, France

\section{Roseline Josée YAPO}

Centre d'Entomologie Médicale et Vétérinaire - Université Alassane Ouattara, Bouaké, Côte d'Ivoire

\section{Kouassi Arsène ADOU}

Institut de Géographie Tropicale - Université Félix Houphouët-Boigny, Abidjan, Côte d'Ivoire, Institut Pierre Richet - Institut National de Santé Publique (INSP), Bouaké, Côte d'Ivoire

\section{Emmanuel TIA}

Centre d'Entomologie Médicale et Vétérinaire - Université Alassane Ouattara, Bouaké, Côte d'Ivoire Florence FOURNET

Centre d'Entomologie Médicale et Vétérinaire - Université Alassane Ouattara, Bouaké, Côte d'Ivoire, MIVEGEC (Uuniv. Montpellier, IRD, CNRS), Institut de Recherche pour le Développement (IRD), Montpellier, France

\section{Research Article}

Keywords: Malaria, LLINs, Usage, Maintenance, Washing, Côte d'Ivoire

Posted Date: January 17th, 2022

DOI: https://doi.org/10.21203/rs.3.rs-1211432/v1 
License: (c) (i) This work is licensed under a Creative Commons Attribution 4.0 International License. Read Full License 
1 Qualitative study on the use and maintenance of Long-Lasting Insecticidal Nets

2 (LLINs) in Bouaké (Côte d'Ivoire), 17 months after the last mass distribution

3 campaign

4 Gnagoran Kouakou Daniel N'GUESSAN ${ }^{1}$, Fangala Hamidou COULIBALY ${ }^{1,2,3}$, Antoine

5 M G BARREAUX ${ }^{4}$, Roseline Josée YAPO ${ }^{1}$, Kouassi Arsène ADOU ${ }^{5,6}$, Emmanuel TIA ${ }^{1}$,

6 Florence FOURNET 1,2

71 Centre d’Entomologie Médicale et Vétérinaire - Université Alassane Ouattara,

8 Bouaké, Côte d'Ivoire

92 MIVEGEC (Uuniv. Montpellier, IRD, CNRS), Institut de Recherche pour le

10 Développement (IRD), Montpellier, France

$11{ }^{3}$ Centre Suisse de Recherches Scientifiques en Côte d'Ivoire, Abidjan, Côte d'Ivoire

${ }^{4}$ Bristol Veterinary School, University of Bristol, Bristol, UK

${ }^{5}$ Institut de Géographie Tropicale - Université Félix Houphouët-Boigny, Abidjan, Côte

d'Ivoire

${ }^{6}$ Institut Pierre Richet - Institut National de Santé Publique (INSP), Bouaké, Côte

d'Ivoire

Corresponding

author: Gnagoran

Kouakou

Daniel

N'GUESSAN,

gnagoran.daniel@uao.edu.ci / gnagoran05@gmail.com

ORCID: https://orcid.org/0000-0002-5866-0146/ 


\section{Abstract}

Background: The long-lasting insecticide-treated net (LLIN) is one of the main malaria prevention tool promoted by the WHO in Côte d'Ivoire. LLIN-coverage has reached 95\% since 2015 and nearly 16 million LLINs were distributed in 2017. Despite these efforts, malaria incidence at the national level remains high (120\%o in 2012 to $164 \%$ in 2017) although this could be partly explained by increased screening efforts. Our goal was to determine the means of protection against mosquitoes as well as the LLIN maintenance practices of the populations in the city Bouaké, capital city of the Gbêkê region with a malaria incidence of $257 \%$ in 2017 .

Methods: An exploratory-descriptive qualitative investigation took place in Bouaké, in four neighbourhoods that were selected through purposive sampling based on their social composition. Data were collected using a questionnaire based on convenience sampling.

Results: The study revealed that LLINs are the most used means of protection (66.4\%). Environmental hygiene was second (28.8\%), smoke coils third $(23.5 \%)$ and aerosol cans last (18.8\%). The proportion of the respondent that slept with an LLIN the night before was of $53 \%$. $57.7 \%$ of respondents washed their LLINs, $12.1 \%$ did not wash them, and $4 \%$ replaced dirty ones with new ones. The LLINs washing methods described by the respondents did not comply with the WHO recommend actions and there was no mention of LLINs repairs.

Conclusion: Despite mass distributions of LLINs in Côte d'Ivoire, this key malaria control tool remains underused by the population. Regarding LLIN maintenance, more than half of the population did wash the nets but without following the recommendations or repairing them. 
Keywords: Malaria, LLINs, Usage, Maintenance, Washing, Côte d'Ivoire

\section{Background}

Malaria is a disease caused by Plasmodium parasites, transmitted to humans by the bite of a female Anopheles mosquito. Malaria is a leading cause of morbidity and mortality in the 91 countries where it is endemic [1]. In Côte d'Ivoire, malaria remains the primary reason for consultation in health facilities despite a national coverage of Long-Lasting Insecticidal Nets (LLINs) estimated at 95\% since 2015 [2]. The number of malaria related cases and deaths recorded in 2017, are 4,032,381 and 3,886 respectively [3]. In 2018, the Regional Health Directorate of Gbêkê, a region located in the centre of the country, recorded 206,378 cases and 106 deaths related to malaria for the capital city of Bouaké. Children under 5 years of age in this city paid the highest price with 58,906 cases and 84 deaths.

Malaria control combines the control of the parasite and of the vector. The former is based on preventive or curative drug treatments and the latter aims at protecting populations from mosquito bites and reducing the intensity of local transmission $[4,5$,

$6,7]$. Vector control reduces human-vector contact, vector longevity and mosquito densities. It is mainly based on the distribution of LLINs and Indoor Residual Spraying (IRS) $[5,8,9,10]$.

At present, LLINs play a very important role in the fight against malaria worldwide by providing a physical and chemical barrier to mosquitoes and they are one of the most effective tools to prevent malaria transmission $[9,11,12]$. In malaria-prone areas, many countries have adopted a LLIN universal coverage policy, as a LLIN coverage of at least $80 \%$ should indeed reduce the malaria burden $[1,13,14,15,16]$. According to the 2016 Multiple Indicator Cluster Survey (MICS), 75.1\% of households in Côte 
d'Ivoire have at least one LLIN and $50.1 \%$ of people slept under LLINs the night before the survey.

Well-maintained LLINs can retain their physical integrity and effectiveness for at least three years $[6,17,18,19]$. To do so, they should be washed with cold water and mild soap, using gentle strokes. They should not be washed more than once every three months and should be dried in the shade. They should also be repaired immediately when they are punctured. It is advised to tie them up when they are not in use $[18,20$, 21].

Factors such as tears, dirt, or improper washing practices may reduce their effectiveness and increase users' risk of contracting malaria [15, 20, 22, 23]. LLINs with holes in them greatly reduce personal protection [24]. Another study in Kenya showed that repeated washing of LLINs over short intervals leads to their biological ineffectiveness [23] demonstrating the importance of following the recommendations. It was confirmed by a study in Benin for Olyset $\AA^{\circledR}$ and PermaNet ${ }^{\circledR}$. However, some nets may be more resistant to improper washing as in the same study the LifeNet@ net remained highly effective against Anopheles gambiae s.s. after repeated washings [25].

Research on community-based LLIN washing practices in Benin has shown that people use traditional soap or Marseille soap to wash their LLINs. LLINs lose their effectiveness when people soak or wash them with traditional soap and let them dry in the sun compared to LLINS washed with Marseille soap and that dry in the shade [26]. A previous study on user perceptions and effectiveness of LLINs in Côte d'Ivoire [27], showed that the use of industrial soap powder and a moderate frequency of washing with tap water maintained the effectiveness of LLINs. An evaluation of the use and maintenance of LLINs conducted as part of an integrated control strategy in a malaria 
endemic area in the Brazilian Amazon, showed that LLINs distributions were not combined with educational strategies conclusive to long-term use [28].

Underutilization of LLINs, as well as poor maintenance practices, could therefore reduce LLINs effectiveness at the community level. These factors may explain why, despite the large-scale distribution of LLINs, the number of cases and deaths related to malaria remains high, especially in Côte d'Ivoire and particularly in the Gbêkê region. The objective of this qualitative study was to determine the preventative measures used by the population against mosquitoes as well as the maintenance and use of LLINs in Bouake.

\section{Methods}

We aimed to understand the knowledge, attitudes, and practices of LLINs use and maintenance regarding the information received. An exploratory-descriptive qualitative investigation was performed, and social representations were collected using the discursive production method [31]. Interviews were conducted on February $26^{\text {th }}$ to $28^{\text {th }}$ , 2019.

\section{Study sites}

The study took place in the city of Bouaké $\left(7^{\circ} 41^{\prime} 00^{\prime}\right.$ north, $5^{\circ} 01^{\prime} 59^{\prime}$ west), capital of the Gbêkê region in central Côte d'Ivoire. Four neighbourhoods were selected by reasoned choice based on their contrasting social composition and housing (Figure 1):

- Cité de l'Air is a recent residential neighbourhood, sparsely populated with modern houses (some still in construction) and bare land covered with scrub.

- Kôkô Aboliba is an old and working-class neighbourhood located downtown and marked by the presence of lowlands. It is characterized by a high population density. It is made up of a population of varied socio-linguistic origin. 
- Ahougnansou Château is a more recent working-class district, located in the third urban extension ring, which began between 1970 and 1980. The built environment is relatively dense with a mix of modern and older housing. There are numerous lowlands.

- Tchèlèkro is a peripheral neighbourhood with a rural characteristic. It is surrounded by a lowland with rice cultures and market gardening. The neighbourhood is growing in density by expanding into cultivated land. The population of this neighbourhood is less cosmopolitan than that of Kôkô Aboliba.

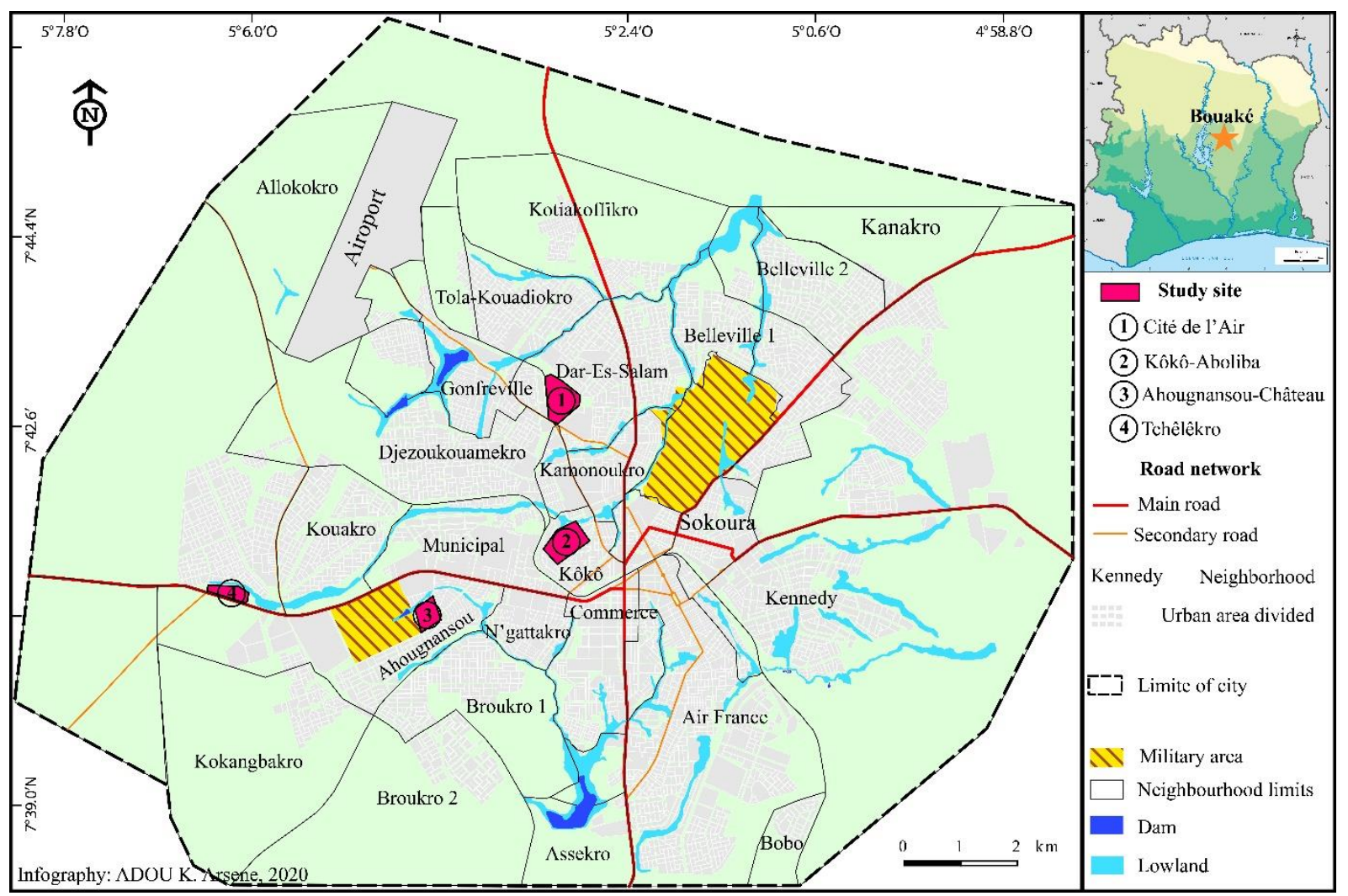

Figure 1: The city of Bouaké and the location of four study districts

\section{Data collection}

Data was collected using an interview guide and the personal interview method (interviewer facing the respondent) [32]. The interview guide consists of 12 questions: three closed questions on the socio-demographic characteristics of the respondents, 
135 two open questions on their knowledge of vector control tools, three closed questions 136 on the use of LLINs, and four questions, two of which are closed, on LLINs 137 maintenance. The non-probability sampling technique was used to construct the 138 sample. In each neighbourhood, the sample was defined on the basis of the saturation 139 of the collected information. Individuals were randomly selected from households and 140 workplaces based on their availability.

\section{Data analysis}

142 The Sphinx V5 software was used to calculate the relative frequencies of the LLINs 143 usage and maintenance indicators. It was also used to extract the content of text variables from the answers to the open-ended questions (verbatim). The excerpts were then presented in lists organized by response category. Content analysis was then used to synthesize the information provided by the open-ended questions and to make

147 sense of it in relation to the context of the study.

\section{Results}

\section{Characteristics of the study population}

150 A total of 149 individuals, 83 men and 66 women, who received LLINs at health centres and during free distribution campaigns were surveyed (Table 1). The age of the respondents ranged from 15 to 73 years old. Two-thirds were 15 to 39 years old, and

153 the remaining third were 40 to 73 years old.

154 Table 1 Sample of respondents by neighbourhood in Bouake

\begin{tabular}{lcc}
\hline Neighbourhood & Sample siżs \\
\hline Kôkô Aboliba & 26 & 156 \\
Cité de l'Air & 50 & \\
Tchèlèkro & 22 & 157 \\
\hline
\end{tabular}




\begin{tabular}{lcc}
\hline Ahougnansou château & 51 & 158 \\
\hline Total & 149 & 159
\end{tabular}

Source: Field survey data, 2019

More than a quarter of the respondents have never attended school and almost $21 \%$

162 went to university (Table 2). There was an important heterogeneity among the 163 neighbourhoods.

Table 2 Educational level of the respondents

\begin{tabular}{lcccc}
\hline Educational & Kôkô Aboliba & Cité de l'Air & Tchèlèkro & Ahougnansou Château \\
level & $\mathrm{n}(\%)$ & $\mathrm{n}(\%)$ & $\mathrm{n}(\%)$ & $\mathrm{n}(\%)$ \\
\hline None & $10(38.5)$ & $15(30)$ & $9(41)$ & $5(9.8)$ \\
Primary & $4(15.4)$ & $6(12)$ & $3(13.6)$ & $10(19.6)$ \\
Middle school & $7(26.9)$ & $2(4)$ & $6(27.3)$ & $9(17.6)$ \\
Secondary & $4(15.4)$ & $14(28)$ & $1(4.5)$ & $13(25.5)$ \\
University & $1(3.8)$ & $13(26)$ & $3(13.6)$ & $14(27.5)$
\end{tabular}

Source: Field survey data, 2019

\section{Means of protection against mosquito bites cited by respondents}

167 Respondents mentioned various vector control methods of which LLINs are the most 168 cited (47\%) (Table 3).

169 Table 3: Vector control tools and methods mentioned by respondents

\begin{tabular}{lc}
\hline Vector control tools and methods & $\mathrm{n}(\%)$ \\
& $(\mathrm{N}=289)$ \\
\hline LLINS & $136(47.0)$ \\
Aerosol cans & $63(21.8)$ \\
Smoke coils & $50(17.3)$
\end{tabular}


Hygiene of the living environment

Fans

Community mosquito spraying

Housing Improvement

Source: Field survey data, 2019

${ }^{*} \mathrm{~A}$ respondent could cite several means of control methods

\section{Vector control tools and methods used by the respondents}

173 LLINs were the more commonly used vector control tools in each neighbourhood. The 174 hygiene of the living environment was less used in Tchèlèkro and Kôkô Aboliba 175 compared to Cité de l'Air and Ahougnansou. A low use of smoke coils was observed at Cité de l'Air. Aerosol cans were used to a greater extent in Cité de l'Air and Tchèlèkro 177 (Table 4).

Table 4: Vector control tools and methods used by the respondents and by

179 neighbourhoods

\begin{tabular}{|c|c|c|c|c|c|}
\hline \multirow{4}{*}{$\begin{array}{l}\text { Vector control tools and } \\
\text { methods used }\end{array}$} & Kôkô Aboliba & Cité de l'Air & Tchèlèkro & Ahougnansou & Overall \\
\hline & $N=33$ & $N=76$ & $N=28$ & Château & $N=209$ \\
\hline & $\mathrm{n}(\%)$ & n (\%) & n (\%) & $N=72$ & n (\%) \\
\hline & & & & n (\%) & \\
\hline LLINs & $18(54.6)$ & 37 (48.7) & 11 (39.3) & $33(45.8)$ & $99(47.4)$ \\
\hline Aerosol cans & $4(12.1)$ & $11(14.5)$ & $5(17.9)$ & $8(11.1)$ & $28(13.4)$ \\
\hline Smoke coils & 7 (21.2) & $8(10.5)$ & $7(25)$ & $13(18.0)$ & 35 (16.7) \\
\hline Hygiene of the living & & & & & \\
\hline environment & $4(12.1)$ & $19(25.0)$ & $4(14.3)$ & $16(22.2)$ & $43(20.6)$ \\
\hline Fans & - & $1(1.3)$ & $1(3.5)$ & $2(2.9)$ & $4(1.9)$ \\
\hline
\end{tabular}

Source: Field survey data, 2019

${ }^{*}$ A respondent could cite several means of control methods 


\section{Willingness to sleep under an LLIN}

Overall, $87.9 \%$ (131/149) of respondents said they were in favour of using an LLIN and $53 \%$ had used it the night before the survey (Table 5). The average use of LLINs the previous night was similar in each neighbourhood. Whatever the neighbourhood, $29.5 \%$ of respondents said they could not remember the last time they had slept under an LLIN. Kôkô Aboliba and Tchèlèkro had higher proportions of respondents who could not remember their last night under a LLIN compared to the average of the four neighbourhoods (38.5\%, $41 \%$ and $29.5 \%$ respectively). $47 \%$ of people having received nets did not use them regularly.

Table 5: LLIN usage by the respondents by neighbourhood

\begin{tabular}{lccccc}
\hline Last night's sleep & Koko Aboliba & Cité de l'Air & Tchèlèkro & Ahougnansou & Overall \\
\multicolumn{1}{c}{ under LLINs } & $\mathrm{n}(\%)$ & $\mathrm{n}(\%)$ & $\mathrm{n}(\%)$ & $\begin{array}{c}\text { Château } \\
\mathrm{n}(\%)\end{array}$ & $\mathrm{n}(\%)$ \\
& & & & $27(52.9)$ & $79(53)$ \\
\hline The night before & $12(46.2)$ & $29(58)$ & $11(50)$ & $3(5.8)$ & $4(2.7)$ \\
Three days ago & & $1(2)$ & & $1(2)$ & $4(2.7)$ \\
Last week & $2(7.7)$ & $1(2)$ & & & $3(2)$ \\
Two weeks ago & $1(3.8)$ & $2(4)$ & & & $3(2)$ \\
One month ago & & $3(6)$ & & $1(2)$ & $2(1.3)$ \\
Two months ago & & & $1(4.5)$ & $6(11.8)$ & $10(6.8)$ \\
Three months ago & $1(3.8)$ & $2(4)$ & $1(4.5)$ & $13(25.5)$ & $44(29.5)$ \\
I don't know & $10(38.5)$ & $12(24)$ & $9(41)$ & $51(100)$ & $149(100)$ \\
\hline Total & $26(100)$ & $50(100)$ & $22(100)$ & & \\
\hline
\end{tabular}

192

Source: Field survey data, 2019

\section{Attitude of the respondents in regard of washing their LLINs}

Of the populations surveyed, $87.2 \%(130 / 149)$ knew that LLINs must be maintained to keep them effective. Only $14.8 \%$ (22/149) of respondents mentioned having received 
196 training on how to maintain LLINs. Respondents' knowledge about LLINs maintenance 197 was dominated by their knowledge and representation of household laundry care. 198 Overall, $57.7 \%(86 / 149)$ of respondents washed their LLINs, $12.1 \%(18 / 149)$ did not 199 wash them, and $4 \%$ (6/149) replaced their dirty LLINs with new ones. $26.2 \%$ of the 200 individuals surveyed did not answer questions about the maintenance of their LLINs.

201 The proportions of people who washed their LLINs were higher in Ahougnansou 202 Château and Cité de l'Air compared to the other two neighbourhoods $(60.8 \%, 70 \%$, 203 42.3\% and $40.9 \%$ respectively). Tchèlèkro had the highest proportion of people who 204 did not respond to this question (Table 6).

Table 6: Attitude to washing LLINs of respondents by neighbourhood

\begin{tabular}{|c|c|c|c|c|c|}
\hline LLINs washing & $\begin{array}{l}\text { Koko Aboliba } \\
\text { n (\%) }\end{array}$ & $\begin{array}{l}\text { Cité de l'Air } \\
\mathrm{n}(\%)\end{array}$ & $\begin{array}{l}\text { Tchèlèkro } \\
\text { n (\%) }\end{array}$ & $\begin{array}{l}\text { Ahougnansou } \\
\text { Château } \\
\text { n (\%) }\end{array}$ & $\begin{array}{l}\text { Overall } \\
\text { n (\%) }\end{array}$ \\
\hline I wash my LLIN & $11(42.3)$ & $35(70)$ & $9(40.9)$ & $31(60.8)$ & $86(57.7)$ \\
\hline $\begin{array}{l}\text { I don't wash my } \\
\text { LLIN }\end{array}$ & $7(27)$ & $5(10)$ & $2(9.1)$ & $4(7.8)$ & $18(12.1)$ \\
\hline $\begin{array}{l}\text { I replace my LLIN } \\
\text { when it is dirty }\end{array}$ & $3(11.5)$ & $2(4)$ & $1(4.5)$ & & $6(4)$ \\
\hline No answer & $5(19.2)$ & $8(16)$ & $10(45.5)$ & $16(31.4)$ & $39(26.2)$ \\
\hline Total & $26(100)$ & $50(100)$ & $22(100)$ & $51(100)$ & $149(100)$ \\
\hline
\end{tabular}

Source: Field survey data, 2019

Detergents used by the respondents to wash the LLINs

208 Four types of detergents were used by the respondents who washed their LLINs. 209 These were OMO (powdered detergent), Savon de Marseille soap, bleach, and 210 Kabakourou (traditional soap). The study revealed that the detergents were either used 
211 individually or in combination (OMO + Savon de Marseille soap, OMO + bleach).

212 Overall, the most used detergent was OMO $(37.3 \%, 28 / 75)$, followed by Savon de

213 Marseille soap $(24 \%, 18 / 75)$ and the combination of OMO + Savon de Marseille soap

$214(17.3 \%, 13 / 75)$ (Table7). 10.7\% (8/75) of respondents washed their LLINs without

215 using any detergent.

216 OMO, Savon de Marseille soap and the combination of OMO and Savon de Marseille

217 soap were used in equal proportions in Kôkô Aboliba (30\%). OMO was the most used

218 detergent in Cité de l'Air (46.7\%) and Ahougnansou (34.6\%). OMO, Savon de Marseille

219 soap, water and the combination of OMO + Savon de Marseille soap was the most

220 used in Tchèlèkro (22.2\%). The use of OMO + bleach, bleach, Kabakourou, or no

221 detergent at all was infrequent in the different neighbourhoods.

222 Tableau 7: Detergents used to wash the LLINs by respondents

\begin{tabular}{|c|c|c|c|c|c|}
\hline LLINs washing & $\begin{array}{l}\text { Koko Aboliba } \\
\text { n (\%) }\end{array}$ & $\begin{array}{l}\text { Cité de l'Air } \\
\mathrm{n}(\%)\end{array}$ & $\begin{array}{l}\text { Tchèlèkro } \\
n(\%)\end{array}$ & $\begin{array}{l}\text { Ahougnansou } \\
\text { Château } \\
\text { n (\%) }\end{array}$ & $\begin{array}{l}\text { Overall } \\
\text { n (\%) }\end{array}$ \\
\hline $\mathrm{OMO}$ & $3(30)$ & $14(46,7)$ & $2(22,2)$ & $9(34,6)$ & $28(37,3)$ \\
\hline $\begin{array}{l}\text { Savon de } \\
\text { Marseille soap }\end{array}$ & $3(30)$ & $9(30)$ & $2(22,2)$ & $4(15,4)$ & $18(24)$ \\
\hline Kabakrou & - & - & $1(11,2)$ & - & $1(1,35)$ \\
\hline Bleach & $1(10)$ & - & - & - & $1(1,35)$ \\
\hline Water & - & - & $2(22,2)$ & $6(23,1)$ & $8(10,7)$ \\
\hline $\begin{array}{l}\text { Omo + Savon de } \\
\text { Marseille soap }\end{array}$ & $3(30)$ & $5(16,7)$ & $2(22,2)$ & $3(11,15)$ & $13(17,3)$ \\
\hline Omo + Bleach & - & $2(6,6)$ & - & $4(15,4)$ & $6(8)$ \\
\hline
\end{tabular}




\begin{tabular}{llllll}
\hline Total & $10(100)$ & $30(100)$ & $9(100)$ & $26(100)$ & $75(100)$
\end{tabular}

Table 8: LLINs washing frequency

\begin{tabular}{lccccc}
\hline Washing frequency & $\begin{array}{c}\text { Koko Aboliba } \\
\mathrm{n}(\%)\end{array}$ & $\begin{array}{c}\text { Cité de l'Air } \\
\mathrm{n}(\%)\end{array}$ & $\begin{array}{c}\text { Tchèlèkro } \\
\mathrm{n}(\%)\end{array}$ & $\begin{array}{c}\text { Ahougnansou } \\
\mathrm{n}(\%)\end{array}$ & $\begin{array}{c}\text { Overall } \\
\mathrm{n}(\%)\end{array}$ \\
\hline $\begin{array}{l}\text { At least once a month } \\
\text { At least once every }\end{array}$ & $6(54,5)$ & $22(62,9)$ & - & $17(54,9)$ & $45(52,3)$ \\
two months & - & $1(2,9)$ & $1(11,1)$ & $5(16,1)$ & $7(8,1)$ \\
$\begin{array}{l}\text { At least once every } \\
\text { three months }\end{array}$ & $2(18,2)$ & $7(20,0)$ & $3(33,3)$ & $2(6,4)$ & $14(16,3)$ \\
At least once every & $1(9,1)$ & $4(11,3)$ & - & $2(6,4)$ & $7(8,3)$ \\
four months & & & & & \\
At least once every & $1(9,1)$ & - & $4(44,5)$ & $4(13,0)$ & $9(10,4)$ \\
six months & $1(9,1)$ & $1(2,9)$ & $1(11,1)$ & $1(3,2)$ & $4(4,6)$ \\
At least once a year & $11(100)$ & $35(100)$ & $9(100)$ & $31(100)$ & $86(100)$ \\
\hline Total & & & & & \\
\hline
\end{tabular}

230

Source: field survey data, 2019

231 Some excerpts from the respondents' open discourse on the maintenance of the LLIN. 
233 "I wash my net when it is dirty. I wash it like I wash my clothes. I wash it once a month with OMO". (Woman, 28-year-old, Koko Aboliba)

236 "I wash every two months when it is dirty with OMO and savon de Marseille soap". 237 (Woman, 32-year-old, Koko Aboliba)

"I wash by hand with soap and OMO every three months". (Man, 19-year-old,

\section{Ahougnansou château)}

240 "I wash with OMO, rinse and dry in shade three time a year". (Man, 20-year-old, Cité 241 de l'Air)

242 "I wash three time a year with soap". (Woman, 19-year-old, Tchèlèkro)

243 "I wash with OMO, and by hand every six months". (Woman, 24-year-old, Cité de l'Air)

244 "I wash with soap and water just every six months". (Man, 65-year-old, Ahougnansou 245 château)

246 "I wash once a year with plain water". (Man, 56-year-old, Ahougnansou château)

247 Source: field survey data, 2019

248 Finally, two trends could be found: "traditional" (Tchèlèkro and Koko Aboliba) and 249 "modern" (Ahougnasou and Cité de l'Air). It can be observed that in Cité de l'Air, the 250 behaviours seemed to be rather in line with the WHO recommendations concerning 251 the recognition of the LLIN as a means of protection against mosquito bites, the need 252 to sleep under the LLIN and to wash it. This is not the case in Tchèlèkro. In Koko 253 Aboliba and Ahougnansou Chateau, the findings were more heterogeneous, but the 254 trend is consistent. 
255 Tableau 8 Summary of results on knowledge, use and washing LLINs by 256 neighbourhood

\begin{tabular}{|c|c|c|c|c|c|}
\hline & Tchèlèkro & $\begin{array}{l}\text { Koko } \\
\text { Aboliba }\end{array}$ & Ahougnansou & $\begin{array}{l}\text { Cité de } \\
\text { l'Air }\end{array}$ & Overall \\
\hline LLINs knowledge & 50.0 & 69.2 & 64.7 & 74.0 & 66.4 \\
\hline $\begin{array}{l}\text { Slept the night } \\
\text { before under LLIN }\end{array}$ & 50.0 & 46.2 & 52.9 & 58.0 & 53.0 \\
\hline Wash LLIN & 40.9 & 42.3 & 60.8 & 70.0 & 57.7 \\
\hline $\begin{array}{l}\text { Wash LLIN every } 3 \\
\text { months }\end{array}$ & 33.3 & 18.2 & 6.4 & 20.0 & 16.3 \\
\hline No answer & 45.5 & 19.2 & 31.4 & 16.0 & 26.2 \\
\hline
\end{tabular}

Source: field survey data, 2019

\section{Discussion}

259 Respondents in the different neighbourhoods reported using several vector control methods to protect themselves from mosquito bites. The LLIN was the most used method (66.4\%). However, this rate clearly shows that the populations of Bouaké are under-using LLINs. Respondents also consider the hygiene of their living environment as a method of protection against mosquito bites. It is less used in traditional neighbourhoods (Kôkô Aboliba and Tchèlèkro) compared to modern ones (Cité de l'Air and Ahougnansou Château). As in modern neighbourhoods, most of respondents have at least secondary education, it could be inferred that socio-economic level and/or education come into play in making people aware that hygiene is important to protect themselves from mosquitoes. Indeed, unhealthy environments appear to favour the exposure to mosquito bites. This component must therefore be taken into account in malaria vector control as it is the case for Aedes control [9]. 
271 There was a moderate use of LLINs the night before in each neighbourhood. This may be due to the lack of community-based health education systems that would encourage people to sleep under LLINs. Only $53 \%$ of all respondents slept under an LLIN the night before the survey even though $87 \%$ were in favour of using them. This rate is well below the $80 \%$ threshold recommended by the $\mathrm{WHO}$, and is roughly equal to the $50.1 \%$ reported by the MICS which dates from 2016 [33] or the 51\% reported in 2020 during the evaluation of an LLIN distribution program in western India [19]. In Nigeria, however, $92 \%$ of respondents reported having slept under an LLIN the night before the survey [34]. Our results indicate that $30.2 \%$ of respondents could not remember the last time they had slept under an LLIN, which makes it clear that LLINs are not frequently used by these persons. As previously hypothesised in another study [28], LLINs were distributed without an educational strategy allowing for their long-term use.

Savon de Marseille soap, industrial powder detergent (OMO) and some use bleach. 
discourses collected on LLINs washing in the different neighbourhoods of our study indicates that the correct washing practices are unknown to the population. This was observed in the four neighbourhoods, which enables us to affirm that awareness of LLIN washing is not associated with the population's living standard and/or education. The practices of the respondents in regard to LLINs maintenance show that their knowledge is dominated by their representation of the maintenance of household linen. This is not suitable for LLINs that should be washed with cold water and mild soap in gentle strokes to maintain their physical integrity and effectiveness for at least three years $[6,17,18,19]$.

Similar results were obtained in Ilorin Kwara State, Nigeria [34] showing that $88 \%$ of the washing was inappropriate. The present study reveals poor maintenance practices for LLINs, in contrast to a previous study in western Kenya [36]. Six respondents said that they do not wash dirty LLINs but replace them with new ones. Replacing LLINs once they are dirty may be due to the fact people are not informed about maintenance, do not say what they actually do, or have enough LLINs to replace the dirty ones. This raises questions about the effectiveness of the mass LLIN distribution strategy [28].

\section{Conclusion}

Our study showed that despite the favourable attitude of the population to sleeping under an LLIN, LLINs remain underused. The different washing methods described show that people are unaware of the WHO recommendations for proper washing of LLINs. It also appears that people's knowledge of how to maintain their LLINs is incomplete, as repairing and knotting were not mentioned in the responses to the openended question on LLIN maintenance. Under-use and lack of knowledge of good maintenance practices for this key malaria control tool can be interpreted as one of the key factors that explains why, despite high coverage of LLINs, the number of malaria 
cases and deaths remains high in Bouake. Identifying the factors limiting the proper use, washing and maintenance of LLINs, and consequently the parameters that could enhance LLIN use, will allow the establishment of community-based health education system to sensitize and train people in the use and maintenance of their LLINs. This could largely contribute to the reduction of malaria transmission in Côte d'Ivoire and more widely.

\section{Statements}

\section{Acknowledgements}

This study is a result of the project aiming to evaluate the residual effectiveness of LLINs in Bouaké. The authors are grateful to the NMCP and CEMV for their support in carrying out this project.

\section{Authors' contribution}

GKDN, FHC and ET made contributions to the conception and design of the study. GKDN, FHC and AMGB analysed the data. GKDN and FHC drafted the manuscript with the contribution of AMGB. All authors were involved in critical revision for important intellectual content. All authors read and approved the final manuscript.

\section{Funding}

The authors thank ABC (Anopheles Biology \& Control) network which funded this project and Professor Jean-Marc HOUGARD for his support to carry out the study.

\section{Availability of data and materials}

All data generated or analysed during this study are included in this published article.

\section{Ethics approval and consent to participate}

This study is approved by the National Malaria Control Program of Côte d'Ivoire. It is part of the fourth policy and strategic orientation of the fight against malaria in Côte 
d'Ivoire, specifically malaria prevention which includes malaria control interventions as well as their surveillance, monitoring and evaluation. Verbal consent was obtained from

347 the respondents prior to the interviews. For those between the ages of 15 and 20, verbal permission from an adult family member was required in addition to consent.

\section{Consent to publication}

350 Not applicable.

\section{Conflict of interest}

352 The authors declare having no conflict of interest.

\section{Authors details}

3541 Centre d’Entomologie Médicale et Vétérinaire - Université Alassane Ouattara, Bouaké, Côte d'Ivoire ; ${ }^{2}$ MIVEGEC (Uuniv. Montpellier, IRD, CNRS), Institut de Recherche pour le Développement (IRD), Montpellier, France ; ${ }^{3}$ Centre Suisse de

Recherches Scientifiques en Côte d'Ivoire, Abidjan, Côte d'Ivoire ; ${ }^{4}$ Bristol Veterinary

School, University of Bristol, Bristol, UK ; ${ }^{5}$ Institut de Géographie Tropicale - Université

Félix Houphouët-Boigny, Abidjan, Côte d'Ivoire ; ${ }^{6}$ Institut Pierre Richet - Institut National de Santé Publique (INSP), Bouaké, Côte d’Ivoire.

\section{References}

1. OMS. Rapport sur le paludisme dans le monde 2016-RESUME. Genève, Suisse; Organisation Mondiale de la Santé; 2017.

2. Ministère de la Santé et de l'Hygiène Publique. Plan national de développement sanitaire 2016-2020. Abidjan, Côte d'Ivoire; Ministère de la Santé et de l'Hygiène Publique; 2016 p. 88. 
3. Ministère de la Santé et de l'Hygiène Publique. Rapport Annuel sur la Situation Sanitaire (RASS) 2017. Abidjan, Côte d'Ivoire; Ministère de la Santé et de l'Hygiène Publique; 2018. p. 391.

4. Barnes KI, Durrheim DN, Little F, Jackson A, Mehta U, Elizabeth A, et al. Effect of artemetherlumefantrine policy and improved vector control on malaria burden in KwaZulu-Natal, South Africa. PLoS Med. 2005; 2(11):e330.

5. Willem T, Bart GJK. Malaria vector control: current and future strategies. Trends Parasitol. 2009; 25(3):101-4. doi: 10.1016/j.pt.2008.12.002.

6. OMS. Entomologie du paludisme et lutte antivectorielle, Guide du participant. Genève, Suisse; Organisation Mondiale de la Santé; 2014.

7. Snow RW, Kibuchi E, Karuri SW, Sang G, Gitonga CW, Mwandawiro C, et al. Changing Malaria Prevalence on the Kenyan Coast since 1974: Climate, Drugs and Vector Control. PLoS ONE. 2015; 10(6): e0128792. doi:10.1371/journal.pone.0128792.

8. Djogbénou L. Lutte antivectorielle contre le paludisme et résistance des vecteurs aux insecticides en Afrique. Med Trop. 2009; 69:160-164.

9. Duvallet G, Fontenille D, Robert V. Entomologie médicale et vétérinaire. Marseille, Versailles: IRD, Quae; 2017.

10. Benelli G, Beier JC. Current vector control challenges in the fight against malaria. Act Trop. 2017; 174:91-96.

11. N'Guessan R, Ngufor C, Kudom AA, Boko P, Odjo A, Malone D, et al. Mosquito Nets Treated with a Mixture of Chlorfenapyr and Alphacypermethrin Control Pyrethroid Resistant Anopheles gambiae and Culex quinquefasciatus Mosquitoes in West Africa. PLoS ONE. 20149(2):e87710. doi:10.1371/journal.pone.0087710. 
12. Vanden Eng JL, Mathanga DP, Landman K, Mwandama D, Minta AA, Shah M, et al. Assessing bed net damage: comparisons of three measurement methods for estimating the size, shape, and distribution of holes on bed nets. Malar J. 2017; 16:405. DOI 10.1186/s12936-017-2049-8

13. Darriet F, Robert V, Tho Vien N, Carnevale P. Evaluation of the efficacy of permethrin impregnated intact and perforated mosquito nets against vectors of malaria.WHO_Mal-84.1008.pdf. Geneva, World Health Organization; 1984.

14. Evans DB, Azene G, Kirigia J. Should gouvernment subsidize to use of insecticideimpregnated mosquito nets in Africa? Implication of a cost-effectiveness analysis. Health Polic and Plan. 1997; 12(2)0:107-114.

15. Darriet F. Moustiquaires imprégnées et résistance des moustiques aux insecticides. Paris: IRD Editions; 2007.

16. Malima R, Emidi B, Messenger LA, Oxborough RM, Batengana B, Sudi W, et al. Experimental hut evaluation of a novel long-lasting non-pyrethroid durable wall lining for control of pyrethroid-resistant Anopheles gambiae and Anopheles funestus in Tanzania. Malar J. 2017; 16:82. DOI 10.1186/s12936-017-1710-6.

17. WHO. Guidelines for laboratory and field-testing of long-lasting insecticidal nets. Geneva: World Health Organization; 2013.

18. United States Agency for International Development (USAID). Intégrer l'entretien des moustiquaires aux stratégies de CCSC relative au paludisme : Guide détaillé. Baltimore, USA: United States Agency for International Development; 2016.

19. Sahu SS, Keshaowar AV, Thankachy S, Panigrahi DK, Acharya P, Balakrishnan V, et al. Evaluation of bio-efficacy and durability of long-lasting insecticidal nets distributed by malaria elimination programme in Eastern India. Malar J. 2020; 19:186. doi: 10.1186/s12936-020-03260-2. 
20. Programme National de Lutte contre le Paludisme (PNLP) du Sénégal. Guide Méthodologique pour la Couverture Universelle en MILDA. Dakar, Sénégal: PNLP; 2011.

21. K4Health. Care of mosquito nets toolkit. 2016. https ://www.k4hea Ith.org/toolk its/care-repai r-LLIN. Accessed 10 Fev 2020.

22. Centre Suisse de Recherche Scientifique (CSRS) en Côte d'Ivoire. CSRS-20102011 Rapport d'activité. Abidjan: CSRS; 2012.

23. Atieli FK, Munga SO, Ofulla AV, Vulule JM. The effect of repeated washing of longlasting insecticide-treated nets (LLINs) on the feeding success and survival rates of $\begin{array}{lllll}\text { Anopheles } & \text { gambiae. } & \text { Malar } & \text { J. }\end{array}$ http://www.malariajournal.com/content/9/1/304.

24. Randriamaherijaona S, Briët OJT, Boyer S, Bouraima A, N'Guessan R, Rogier C, et al. Do holes in long-lasting insecticidal nets compromise their efficacy against pyrethroid resistant Anopheles gambiae and Culex quinquefasciatus? Results from a release-recapture study in experimental huts. Malar J. 2015; 14:322. Doi: 10.1186/s12936-015-0836-7.

25. Agossa FR, Padonou GG, Gnanguenon V, Oké-Agbo F, Zola-Sahossi J, Dègnonvi $\mathrm{H}$, et al. Laboratory and field evaluation of the impact of washings on the effectiveness of LifeNet ${ }^{\circledR}$, Olyset ${ }^{\circledR}$ and PermaNet $\AA 2.0$ in two areas, where there is a high level of resistance of Anopheles gambiae to pyrethroids, Benin, West Africa. Malar J. 2014; 13:193. http://www.malariajournal.com/content/13/1/193.

26. Kelani R, Aïtchedji M, Yadouleton A, Allagbe H, Issaou G, Degla S. Utilisation des moustiquaires imprégnées à Longue Durée d'action (MILD) au Bénin contre le paludisme: impacts des pratiques de lavage en milieu communautaire sur leur efficacité. Innov Spac of Scient R J. 2014; 7:4. http://www.ijias.issr-journals.org/. 
441 27. Doudou DT, Amoikon MI, Ani A, Konan YL, Doannio JMC. Perceptions des 442 utilisateurs de l'efficacité des moustiquaires imprégnées d'insecticide à longue 443 durée d'action (MILDS) dans les conditions de terrain en Côte d'Ivoire. Europ Sc J. $444 \quad 2012 ; 8(11): 34-54$.

445 28. Sousa JO, Albuquerque BC, Coura JR, Suarez-Mutis MC. Use and retention of 446 long-lasting insecticidal nets (LLINs) in a malaria risk area in the Brazilian Amazon:

447 a 5-year follow-up intervention. Malar J. 2019; 18:100. $448 \quad$ https://doi.org/10.1186/s12936-019-2735-9.

449 29. Abric J-C. Pratiques sociales et représentations. Paris: PUF; 1994.

450 30. Jodelet D. Représentations sociales : un domaine en pleine expansion. Paris: PUF; $451 \quad 1989$.

452 31. Valence A. Les représentations sociales. Bruxelles: De Boeck; 2010.

453 32. Berthier N. Les techniques d'enquête en sciences sociales. Méthodes et exercices 454 corrigés 4ème édition. Paris: Armand Colin, 2010.

455 33. MICS. La situation des femmes et des enfants en Côte d'Ivoire. Abidjan: Ministère 456 du Plan et du Développement, Institut National de la Statistique; 2016.

34. Obembe A, Anyaele OO, Oduola AO. Lessons from the implementation of LLIN distribution campaign in Ilorin Kwara State, Nigeria. BMC Public Health. 2014; 14:517. http://www.biomedcentral.com/1471-2458/14/514.

35. Atkinson J-A, Bobogare A, Fitzgerald L, Boaz L, Appleyard B, Toaliu H, et al. A qualitative study on the acceptability and preference of three types of long-lasting insecticide-treated bed nets in Solomon Islands: implications for malaria elimination. Malar J. 2009; 8:119. Doi: 10.1186/1475-2875-8-119. 
464 36. Santos EM, Coalson JE, Jacobs ET, Klimentidis YC, Munga S, Agawo M, et al. Bed 465 net care practices and associated factors in western Kenya. Malar J. 2019; 18:274. $466 \quad$ https://doi.org/10.1186/s12936-019-2908-6. 